\title{
El agua en la región de la Chinantla, México. Estudio comparativo de una cosmovisión chinanteca a partir de su tradición oral.
}

\author{
Water in the Chinantla region, Mexico. \\ Comparative study of a Chinantec worldview \\ based on their oral tradition.
}

\author{
Marcos Núñez Núñez \\ (CONACYT-Universidad del Papaloapan-Tuxtepec) \\ duritoborges@hotmail.com \\ ORCID ID: 0000-0003-4710-6294
}

\begin{abstract}
In this article, eight stories from the Chinantec oral tradition are mentioned and compared. Half of them correspond to a compilation by anthropologist Robert $\mathrm{J}$. Weitlaner, from the middle of the 20th century, and the other half was obtained between 2015 and 2016 in the municipalities of Santa María Jacatepec and San José Chiltepec, located in the same region, known as the Chinantla. The only requirement for the study was that the topic of water was present in the texts. This exercise allowed observing the importance of water resources in the Chinantec worldview, its recurrence and persistence in tradition, despite the changes caused by the social development policies promoted by the Mexican government, which impacted on natural resources. However, the comparison will serve to demonstrate that, from the similarities arise the possible differences between both corpuses. These are related to the historical context in which the stories were compiled.
\end{abstract}

KEYWORDS: water, oral tradition, worldview, chinantec, Weitlaner
RESUMEN. En el presente artículo se citan y comparan ocho relatos de la tradición oral chinanteca. La mitad de ellos corresponden a una compilación del antropólogo Robert J. Weitlaner, hecha a mediados del siglo XX y la otra mitad fue obtenida entre los años 2015 y 2016 en los municipios de Santa María Jacatepec y San José Chiltepec, ubicados en la misma región conocida como la Chinantla. El único requisito para hacer el estudio fue que el tópico del agua estuviera presente en los textos. Dicho ejercicio permitió observar la importancia de los recursos hídricos en la cosmovisión chinanteca, su recurrencia y persistencia en la tradición a pesar de los cambios ocasionados por las políticas de desarrollo social impulsadas por el gobierno mexicano, las cuales impactaron sobre los recursos naturales. No obstante, la comparación permitirá demostrar que desde las similitudes surgen las probables diferencias entre ambos corpus, relacionadas con el contexto histórico en que fueron compilados los relatos.

PALABRAS-CLAVE: agua, tradición oral, cosmovisión, chinantecos, Weitlaner. 


\section{INTRODUCCIÓN}

La mayoría de los chinantecos viven en el norte del estado de Oaxaca, en la frontera con Veracruz, y a su región se la conoce como la Chinantla. El antropólogo Robert J. Weitlaner estudió esta comunidad durante el siglo XX hasta su muerte en 1967. En numerosas ocasiones anduvo tanto en las partes bajas como en las altas de dicha región. Esto lo llevó a realizar una obra que a la fecha es fuente de consulta obligada para los antropólogos en el siglo XXI. Como bien mencionan sus biógrafos, no todo lo que Weitlaner aprehendió entre los chinantecos se publicó y entre lo que sí se editó, no todo se analizó. Tal es el caso de la amplia colección de textos publicados por el Instituto Nacional Indigenista (INI) en 1977, el cual tuvo por título: Relatos, mitos y leyendas de la Chinantla y que es revisada en esta ocasión con el objetivo de analizar la cosmovisión chinanteca relativa al agua. En particular, esta compilación es evidencia de trabajos de campo, ha sido estudiada parcialmente y a la fecha demanda atención, debido a que actualmente participo en un proyecto académico sobre turismo en la subregión baja. En este sentido, lo estudiado en dicha fuente servirá para un estudio comparativo que contrastará la evidencia de Robert J. Weitlaner con la aprehendida por mí entre los años 2015 y 2016.

El presente artículo corresponde al proyecto de Cátedras CONACYT que se lleva a cabo en la Universidad del Papaloapan, campus Tuxtepec, cuyo título es: Análisis sociocultural-económico que permita el desarrollo turístico sostenible en la ruta de la Chinantla, el cual se conforma de tres líneas de compilación y análisis de información, que son los aspectos sociales, económicos y culturales. Siendo este último el que me ha correspondido atender con la intención de considerar el tema cultural como íntimamente relacionado con el turismo. En este sentido, el proceso de trabajo ha seguido la línea de Zamorano (2007: 289-295), quien ayuda a entender que un desarrollo turístico alternativo, como es el que se podría implementar en la Chinantla, habrá de tener en la naturaleza y en las expresiones tradicionales sus principales recursos de explotación. Al respecto se tiene en cuenta que en el caso de la relación entre los pueblos chinantecos (como sucede en cualquier sociedad) y la naturaleza, la mediación fundamental es la cultura a partir de la cosmovisión. Ahora bien, de las posibilidades que puede haber en esta relación, he escogido solo una, la que tiene que ver con el agua. Al mismo tiempo, decidí que los objetos de estudio fueran los relatos provenientes de la tradición oral que tengan como un elemento narrativo a este recurso natural, porque permitirían hacer una aproximación a la importancia que tiene en la sociedad chinanteca; asimismo, esto daría margen para estimar el impacto que podría tener el turismo sobre el agua no solo como recurso económico, sino también como aquel que forma parte de la cultura.

De este modo, una vez que comencé a hacer trabajos de campo en los municipios de Santa María Jacatepec y San José Chiltepec, y viendo los avances en torno a la compilación de relatos tradicionales, revisé los textos aprehendidos por Robert. J. Weitlaner y fue así que surgieron las siguientes preguntas: ¿Qué importancia tiene el agua en la cosmovisión de los chinantecos visitados por Weitlaner? ¿Cuál es el sentido que tiene actualmente entre los habitantes de los municipios de Jacatepec y Chiltepec, teniendo en cuenta que son municipios chinantecos? ¿Cómo observar esta importancia en ambos casos a partir de relatos de tradición oral? Lo que sigue a continuación es la presentación de resultados, cuya intención es mostrar la concepción que se tenía y se tiene del agua, observando las diferencias y coincidencias entre ambos corpus. 
La hipótesis que planteé asumía que el agua continuaba siendo un elemento natural de relevancia, debido a las características geográficas que en buena parte corresponde a la cuenca del Papaloapan. Al respecto argumenté que esto se notaría en la producción de relatos, con la mención de ríos, lagunas o arroyos, al ser los elementos acuíferos de mayor presencia en el ecosistema. También desde un principio supuse que habría tendencias similares en cuanto a los géneros y motivos narrativos presentes en los dos corpus. Sin embargo, demostraré cómo a pesar de dichas similitudes y continuidades, existen matices diferenciantes que son resultados del proceso de cambio cultural que ha sufrido la sociedad chinanteca en las últimas décadas.

El método utilizado combinó la consulta bibliográfica, la etnografía y el análisis de textos a partir de un procedimiento comparativo que tomó en cuenta determinados motivos, es decir, aquellos contenidos narrativos estables en los relatos y variables en el discurso, los cuales pueden aparecer en otros textos sin dejar de ser ellos mismos (Cuéllar, 2013: 124) ${ }^{1}$. Para este fin, revisé publicaciones sobre la región, poniendo atención en datos históricos y los relacionados con la tradición oral. Fue en esta fase que observé la obra de Robert J. Weitlaner. Simultáneamente hice recorridos etnográficos y recopilé relatos orales. Ya en un momento posterior, para atender el tema del agua, seleccioné los textos que lo tenían como un tópico importante, lo cual dio como resultado la cantidad de diecisiete versiones de las cuales hice una clasificación a partir de motivos. Una vez realizada esta parte, procedí al análisis de los elementos comunes y diversos entre ambos corpus, de tal suerte que fuera posible extraer conclusiones que posibilitarían la redacción de este trabajo.

La exposición inicia con una breve descripción de la Chinantla, poniendo atención en el tema del agua. Inmediatamente paso al estudio del corpus de Robert J. Weitlaner, que incluye una biografía breve y una revisión de conceptos que se mencionan en el libro. Posteriormente cito y reviso los textos elegidos para el análisis, destacando los motivos que permitirán observar el agua y su lugar en la cosmovisión chinanteca. Para esto, debo decir que para mí la cosmovisión es «una visión estructurada y coherente del mundo natural, de la sociedad y resultante de la interpretación entre ambos» (Broda, citada por Good, 2001: 240), la cual es histórica y cambiante. Al terminar esta parte, hago lo mismo con el caso de la narrativa oral contemporánea. Al final, sigue mi ejercicio comparativo que permitirá extraer conclusiones. Para esta parte, informo que la forma de exposición se inspiró en el trabajo de James Taggart (1983), quien hizo un ejercicio similar con la tradición oral de los nahuas del estado de Puebla.

\section{CONTEXTO REGIONAL DEL AGUA}

A la Chinantla la integran catorce municipios que en total tienen 138,741 habitantes (INEGI, 2015) y corresponden a los distritos de Tuxtepec, Choapam, Ixtlán y Cuicatlán (De Teresa, 2011: 17). En relación a su situación geográfica, la región ocupa por lo menos el 10.7 por ciento de la selva tropical húmeda que hay en el territorio mexicano, según datos de Ana Paula de Teresa (Ídem); se caracteriza por ser de clima caluroso-húmedo en las partes bajas y frío, aunque también muy húmedo, en las zonas altas. Actualmente existen tres subdivisiones regionales basadas en sus condiciones ecogeográficas: por un lado está la Chinantla alta, ubicada a más de mil metros sobre el nivel del mar; la Chinantla media, que se encuentra entre los cuatrocientos y mil metros y la baja, que en su nivel más alto no rebasa los cuatrocientos metros de altura (Ibíd.: 20).

\footnotetext{
${ }^{1}$ Ver también los trabajos de Raúl Eduardo González (2014: 61) y Martha Isabel Ramírez González (2012: 64-66).
} 
Algo importante en la región es su riqueza por la presencia de agua. Las lluvias son abundantes, aunque no a tal grado como dijera Bernard Bevan, quien afirmó que «hay un agudo contraste con todo el resto de México, porque no existe una estación seca en el área chinanteca» (1987: 25). Si bien en esta región llueve mucho, podría decirse que lo hace principalmente en verano, otoño e invierno, porque en primavera hay un período de secas que permite a algunos chinantecos abajeños trabajar en el campo a la espera de las lluvias de junio o julio. Para el caso de las zonas media y alta, Ana Paula de Teresa dice que se distinguen «por su alta precipitación durante todo el año» (Ibíd.: 24). En este sentido, las lluvias más copiosas suceden en los meses de julio a noviembre, algunas acompañadas de tormentas que generan crecimientos de ríos, formación de cascadas e intensa humedad.

El agua está presente en forma ríos, lagunas y arroyos, además de las dos presas hidroeléctricas que se construyeron desde la segunda mitad del siglo pasado. La cuenca fundamental es la del río Papaloapan, cuyo sistema lótico incluye entre otros ríos al Valle Nacional. Asimismo, debo mencionar que la población tiene un estrecho vínculo con los recursos acuíferos a nivel de cosmovisión, tal y como Virginie Thiébaut (2013) lo ha demostrado en las comunidades asentadas en torno al río Papaloapan, las cuales han desarrollado una forma de vida y cultura específicas.

En la región el agua obviamente ha tenido relevancia económica, lo cual es demostrable al observar el patrón de asentamiento poblacional. Del mismo modo, su abundancia ha posibilitado la instauración de industrias en San Juan Bautista Tuxtepec, la ciudad más importante en torno a la Chinantla, donde se instalaron, desde la década de 1960, una azucarera, una fábrica de papel y especialmente una cervecera del Grupo Modelo, la cual se abastece del agua que pasa por el río al ser una de sus materias primas, tal y como refiere Tomás García Hernández (1997).

Tal es la relevancia del vital líquido, que incluso ha sido factor decisivo en problemas sociales generados por las inundaciones. De hecho, la de 1944 es histórica, porque dejó en estado de desastre a comunidades chinantecas y otras en la cuenca del Papaloapan, en los estados de Oaxaca y Veracruz (Ibíd.: 111-118). Esto motivó al gobierno federal a tomar medidas de política pública para evitar que sucedan más catástrofes. Por lo que durante la gestión del presidente Miguel Alemán se creó, a partir de la Secretaría de Agricultura y Recursos Hidráulicos (SARH), la Comisión del Papaloapan (CODELPA), cuya misión fue la modernización de esta región a partir de la creación de una infraestructura estratégica (Bartolomé y Barabas, 1990: 13-15), por lo que se planeó la construcción de presas, carreteras, escuelas y centros de salud; se propuso además la electrificación de numerosas localidades, muchas de ellas chinantecas. Para el caso de los municipios estudiados aquí, significó un cambio importante, porque se construyó la carretera 175, que va de Tuxtepec a Oaxaca y que cruza precisamente por las localidades de Chiltepec y Jacatepec.

En este proceso de modernización iniciado con la CODELPA, debe subrayarse la importancia que tuvo la construcción de las dos presas. La primera, Miguel Alemán, se construyó entre los años 1949 y 1955, se ubicó en Temazcal sobre el río Tonto (De Teresa, Op. cit:: 95), afectó principalmente al pueblo mazateco, al tener que ser removido de algunas de sus localidades y fundar otras en sitios designados por la planificación, la cual incluyó la entrega de viviendas con sus servicios básicos. Numerosas familias fueron reubicadas en el municipio de Jacatepec, fundando los pueblos de La Joya y Nuevo Málzaga. La otra presa, llamada José López Portillo, o Cerro de Oro, se construyó entre 
los años 1973 y 1989, afectó en esta ocasión a la comunidad chinanteca, especialmente a la que pertenecía a los municipios de San Lucas Ojitlán y San Felipe Usila (ibíd.: 96).

Los consecuencias ocasionadas por estas construcciones se apreciaron en los otros municipios de la Chinantla baja, como sucedió en Chiltepec y en Jacatepec, donde las personas advirtieron cambios en la pesca e incluso en las posibilidades de navegación en la ribera del río Valle Nacional, que es el que los cruza y que a su vez es un afluente conectado al Papaloapan. En palabras de un vecino oriundo de Chiltepec, la apreciación del cambio en torno al río es la siguiente:

Con el tiempo el río se fue poniendo bajo, los chalanes se varaban, se quedaban en las playas y tenían que meter yuntas, mulas para volver a poner a flote esas navegaciones que había; luego vino lo de la presa Cerro de Oro y vino más a darle al traste a este río de Jacatepec, porque construyeron la presa en el río Santo Domingo que era afluente del Valle Nacional, porque al frenar el Santo Domingo el Valle Nacional se perjudicó y quedó más bajo. Eso acabó con la vida del río. Anteriormente aquí se pasaba con una chalupa, porque era muy hondo, tenía que echarse a andar con remo, ahora ya puedes pasar caminando en el agua en ciertas temporadas del año, porque el río ya se hizo bajo. Al estar así, pues el agua se calienta más y se vuelve difícil para las formas de vida de los peces que antes había. N'ombre, las presas vinieron a traer puros daños para la economía de los jacatepenses y para la ecología, porque perjudicó la fauna y la flora. Por eso a veces decimos que vivimos en una región dañada y que ya no es auténtica, porque hubo cambios muy fuertes con la construcción de las presas ${ }^{2}$.

La importancia de este río es tal que el asentamiento de Chiltepec y Jacatepec se ubica en sus orillas. Por esta cuestión ambas localidades vecinas comparten procesos históricos desde el periodo colonial, más allá de sus diferencias lingüísticas y culturales, porque el agua ha sido y es uno de sus principales recursos económicos, componente principal de sus paisajes y sus tradiciones. En este sentido los cambios y las afectaciones, tal como refirió Joel Avendaño, son sistémicos para ambas.

El agua en el municipio de Jacatepec se encuentra también en forma de arroyos, ojos de agua y tiene usos diversos. En localidades como Cerro Concha o El Guayabo, el arroyo es utilizado para el aseo personal, la preparación de los alimentos y también para lavar la ropa sobre las piedras. En el pueblo de Vega del Sol hay un manantial conectado con el río Valle Nacional y que ha sido adaptado como balneario con el nombre de El Zuzul; este espacio es uno de los más concurridos en la región, porque a él arriban turistas de Tuxtepec, Loma Bonita e incluso de la ciudad de Oaxaca. No obstante, el agua en Vega del Sol, a pesar de estar funcionando para el turismo, se utiliza para actividades domésticas; de hecho, es sobre este lugar del cual se cuentan narraciones orales, como referiré más adelante. Por su parte en Nuevo Málzaga el paso del río Cajonos es utilizado para dar de beber al ganado, regar las siembras y también como balneario; en la localidad de San Martín, por su parte, las autoridades utilizan el paso del río Valle Nacional como balneario y así obtienen ingresos para beneficio comunitario y el mantenimiento de dicho espacio; finalmente en La Joya, en Loma del Carmen y en otras localidades vecinas, sus arroyos son explotados con bombas eléctricas para abastecer de agua a las viviendas.

\footnotetext{
${ }^{2}$ Entrevista con Joel Avendaño el 30 de mayo de 2015 en Jacatepec.
} 


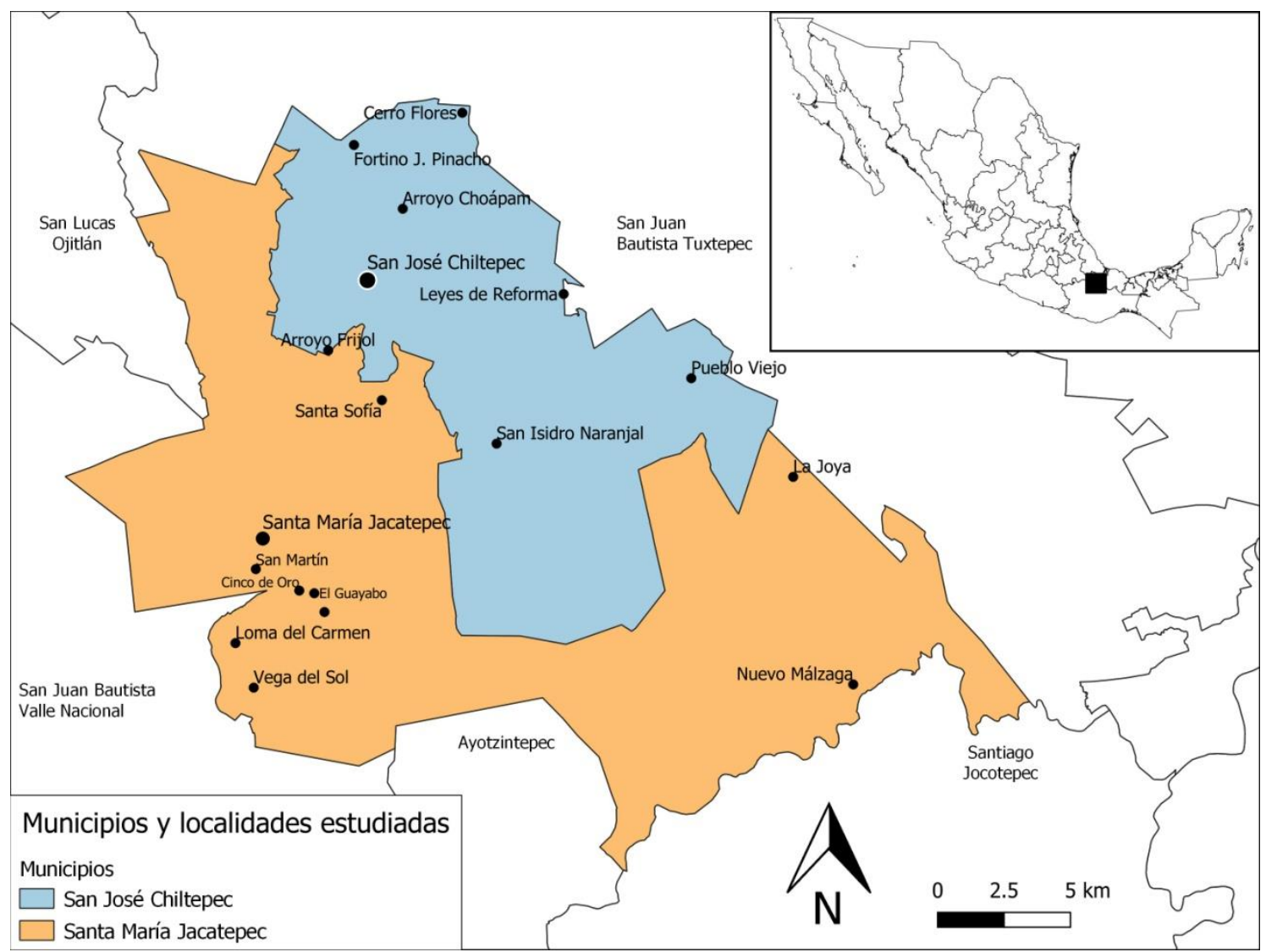

[Mapa 1. Ubicación de las localidades de estudio. Elaboración Marcos Núñez Núñez a través de QGIS, datos del INEGI y CONABIO.]

Por el lado de Chiltepec, sucede algo similar. Especial atención merece el poblado San Isidro Naranjal, donde hay un balneario llamado Cascada del Arcoíris, el cual tiene como atractivo precisamente las cascadas que se forman en verano y otoño a causa de las lluvias. Durante ese periodo el sitio es visitado por turistas, que generalmente llegan con sus propios automóviles a pesar de las difíciles condiciones del camino. Esta afluencia ha sido tomada en cuenta por las autoridades, que han organizado comités de tal modo que sea posible el mantenimiento del espacio. Otros poblados, como Arroyo Frijol, Pueblo Viejo, Leyes de Reforma o Cerro Flores, cuentan con el paso de arroyos, los cuales son utilizados generalmente para el abastecimiento de las viviendas, el lavado de autos y en menor medida como balnearios atractivos para visitantes foráneos. A pesar de esto, los paisajes de estas localidades son apreciados por las pocas personas que los visitan, especialmente en Arroyo Frijol y Leyes de Reforma. Es interesante, por su lado, el pueblo Arroyo Choapan, que cuenta con dos lagunas, una llamada Lechuga y la otra Campana. Esta última tiene peculiar importancia, porque además de servir como espacio de recreación local, también es identificada en la tradición oral a partir de una leyenda de encantamiento.

Por la cabecera municipal, Chiltepec, pasa el río Valle Nacional, el cual es utilizado para la navegación ligera, la pesca, el consumo doméstico, el lavado de ropa, también en actividades recreativas como sucede con sus balnearios El Romance y el de la Colonia Reforma. Ambos sitios cuentan con tinglados de palma ocupados para la venta de antojitos o para el descanso bajo la sombra. Por último, debo mencionar el pueblo de Fortino Pinacho, donde hay un balneario abastecido por dos manantiales y que además 
cuenta con el paso del río Valle Nacional; el sitio se considera a sí mismo como turístico, impulsado por las autoridades locales y que aspira a consolidarse a nivel regional; su mejor temporada para los visitantes es en primavera y deja de ser atractivo cuando inicia la temporada de lluvias.

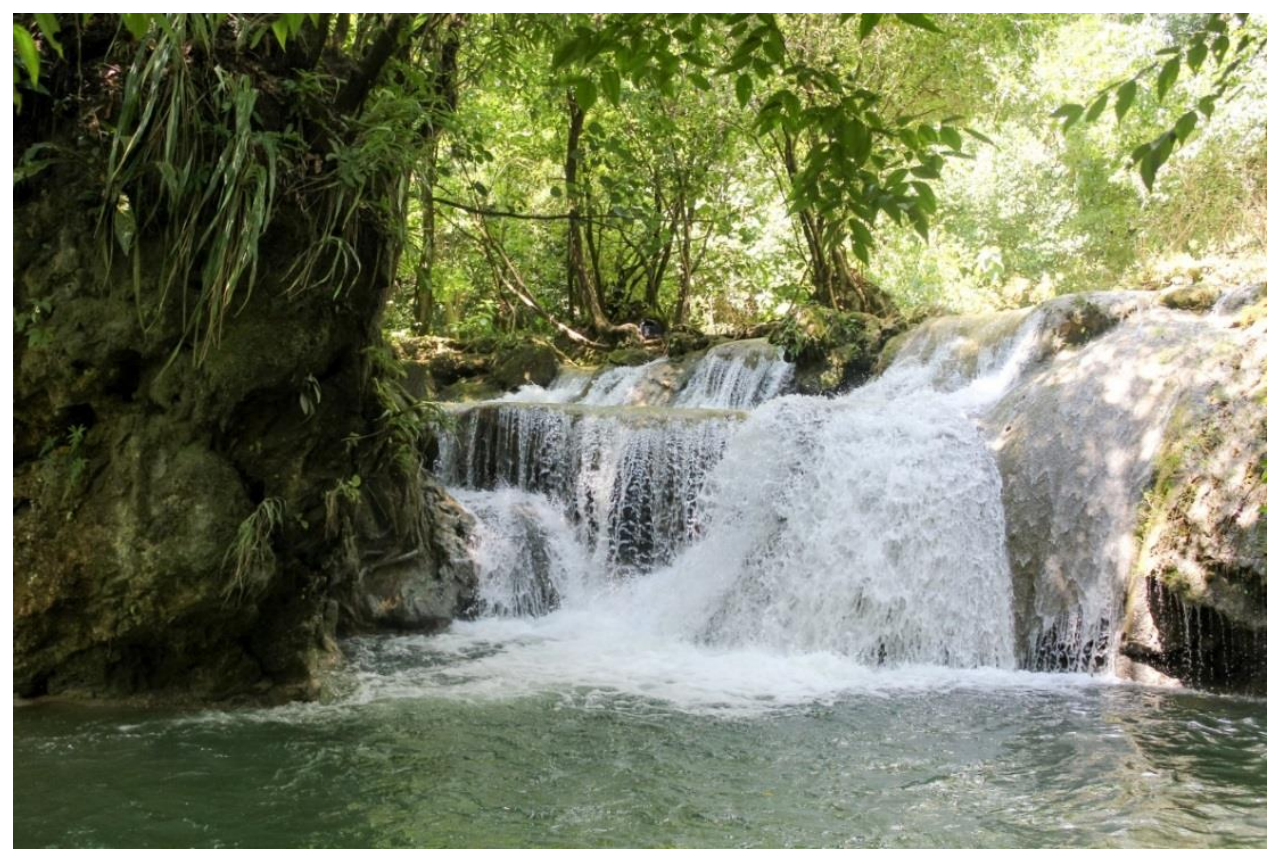

[Cascada de San Isidro Naranjal, municipio de San José Chiltepec.]

\section{LOS RELATOS COMPILADOS POR ROBERT J. WEITLANER}

El libro Relatos mitos y leyendas de la Chinantla es mi principal fuente de análisis. No obstante, revisé diversos títulos para conocer mejor el contexto que posibilitó la elaboración de dicho libro (por ejemplo Weitlaner y Castro, 1973). Su publicación fue en 1977, cuando Roberto J. Weitlaner cumplía precisamente diez años de haber fallecido. Las autoras de la selección de relatos, introducción y notas fueron María Sara Molinari, María Luisa Acevedo y Marlene Aguayo Alfaro. Hasta la fecha el volumen cuenta con dos ediciones y la que utilizo aquí es la primera. Cuenta con un prólogo que menciona datos biográficos sobre Robert J. Weitlaner, que sirven para recordarlo como un antropólogo ejemplar radicado en México y que fue profesor de numerosas generaciones de antropólogos. Le sigue una nota preliminar donde dice que los materiales orales fueron extraídos de un conjunto de documentos resguardados por el Instituto Nacional de Antropología e Historia (INAH). El libro prosigue con un bosquejo biográfico, en el cual se agrega que Weitlaner estudió también otras sociedades mesoamericanas, como los mixes, los cuicatecos, los nahuas, entre otros.

La introducción del libro contiene datos en torno a la tradición oral. Se menciona que Robert J. Weitlaner tomaba en serio las narraciones que los chinantecos hacían de su historia, registrando de distintas maneras cada uno de los testimonios. Grababa en cintas de audio, pero cuando no era así, tomaba notas a mano y en ocasiones utilizando la taquigrafía. Más adelante, las editoras refieren que el registro de la tradición oral paulatinamente pasó a ser su trabajo primordial, ya que el corpus se incrementó con los años. Más adelante se menciona el tipo de relatos que se encuentran en el libro, que son: mitos, leyendas, cuentos, memoratas y creencias. Todos estos géneros son definidos en dicha parte y fueron de especial interés para la presente investigación, ya que al utilizarlos 
permitieron hacer las comparaciones en la misma línea de criterios conceptuales sobre los géneros narrativos.

En este sentido, utilizo la palabra relato para referir los textos narrativos independientemente de su género (Weitlaner, 1977: 28). El mito es comprendido como el texto «que alude a aspectos como los orígenes, la cosmovisión y los modelos de moralidad expresados en forma alegórica o simbólica» (Ídem). De la leyenda se menciona que tiene un trasfondo histórico o que parte de un hecho que en realidad sucedió, pero que al ser narrado continuamente en la tradición, los hechos coexisten con otros fabulosos o fantásticos (Ídem). El cuento por su parte es comprendido como un relato de hechos totalmente ficticios, el cual «puede referirse a asuntos humanos, animales o cósmicos, pero tratados con fantasía» (Ídem). Finalmente, para fines comparativos, el concepto de memorata aquí es relevante, porque narra «experiencias personales conectadas con seres o sucesos sobrenaturales, ocurridos al propio relator o a una tercera persona en quien el relator indudablemente confía. Frecuentemente este tipo de narraciones dan una idea de ciertas creencias y de cómo son aplicadas en casos concretos» $(\text { Ídem })^{3}$.

Una vez citadas las definiciones y planteado el contexto de la obra, informo que en esta fuente revisé diecisiete relatos relacionados con el agua, de los cuales elegí cuatro representativos de distintos motivos que comentaré al término de cada uno. De este modo, el primer texto se titula: Sobre el padre y la madre del maíz, compilado en 1954. Dice así:

En los llanos de Ozumacín, había una gran laguna, los ancianos decían que en esta gran laguna estaban el padre y la madre del maíz y también del algodón. Por eso no querían bañarse en este lugar, porque había aire y rayo. Solamente divisaban desde lejos esta laguna.

La laguna se secó en el tiempo de cuando las fincas se pusieron por estas partes y entonces el padre y la madre del maíz y del algodón se fueron a Jocotepec y ahí se encuentran ahora, allá (cosechan) mucho maíz y mucho algodón (Ibíd.: 90).

El relato refiere cómo el agua, representada aquí en forma de laguna, tenía un lugar preciso dentro de la cosmovisión. Era el sitio específico de las entidades sagradas que abastecían con recursos de subsistencia a quienes las respetaban. En Ozumacín la gente no se bañaba en la laguna porque había una carga simbólica que daba coherencia y formaba parte de su sistema de creencias. Una vez que se secó, la explicación que se dio a esta situación no dejó de estar vinculada con la cosmovisión, porque hubo una especie de culpa y por tanto, un castigo por la incursión de actividades de explotación comercial de los recursos, lo cual ocasionó que las entidades sagradas llevaran sus bendiciones a Jocotepec, un lugar donde quizá recibían el debido respeto. En relación al género narrativo de este relato, se dice que es una leyenda etiológica, es decir, tiene que ver con sucesos que efectivamente sucedieron, pero que se han entremezclado con elementos fantásticos, además de que el relato da cuenta de un proceso de cambio iniciado con la modernización económica.

Los motivos a considerar para el análisis, son: 1) el agua y su relación con entidades sagradas o sobrenaturales, 2) transgresión del orden cosmogónico, 3) el agua en forma de laguna y 4) uso doméstico del agua.

\footnotetext{
${ }^{3}$ Las memoratas son conocidas en otros estudios como «casos», por ejemplo en el trabajo de Gabriel Medrano y José Manuel Pedrosa (2018).
} 
El segundo texto se titula La gente del río, fue compilado en Ojitlán sin mencionar en qué año. Dice así:

Un amigo de don Sabino (narrador del relato) llamado Lorenzo, fue con cinco compañeros al río a cohetear en un lugar cerca de la raya con Usila. Mataron diez peces, pero a un bobo que también habían matado, no podían sacarlo del río ${ }^{4}$. Este bobo estaba abajo, en un pozo. Una de las gentes buceaba, pero no pudo levantar al bobo. Hasta seis veces se metió abajo del agua y no pudo sacarlo. Un hombre dijo:

-Busquen una pita para sacarlo.

Entonces bajó una víbora hasta donde estaba el bobo muerto. La gente dijo al amigo que propuso lo de la pita.

-Déjalo, (esa víbora) es gente del río.

—No, — dijo el pescador Lorenzo - yo lo voy a sacar a la fuerza.

(Intentó) Pero al fin regresó con los otros al pueblo.

Después de un mes, Lorenzo cayó enfermo y habló a un curandero. Éste le preguntó si había ido a pescar al río.

- Sí - contestó Lorenzo.

- Allí está una serpiente grande - dijo el curandero- ¿Por qué quisiste sacar un bobo a la fuerza? Esa (serpiente) es un jefe de animales, pero voy a ir al río donde está el pozo con cuatro hombres para pedir perdón al jefe.

Fue al río diez veces y pidió perdón. Pero el enfermo no se alivió. Fue hasta México, pero ni esto le ayudó. No sanó y después de seis meses se murió (Ibíd.: 127-128).

Este relato contiene pistas de cómo el río tiene especial vinculación con la cosmovisión. Según Weitlaner y Castro (1973: 50), además de Molinari y Aguilar (2013: 23), los chinantecos consideran que muchos animales, tanto terrestres como acuáticos tienen sus jefes o dueños sobrenaturales, a los cuales hay que respetar e incluso tratar con cuidado, ya que de lo contrario puede pasar lo que le sucedió a Lorenzo. Esos dueños son seres que adquieren diversas representaciones, sean de animales acuáticos o terrestres vinculados con el agua y la humedad. Llama la atención la aparición de una serpiente, un animal terrestre que abunda en las inmediaciones de los ríos o lagunas. ${ }^{5}$ En el ejemplo que acabo de referir, se aprecia cómo el río se interrelaciona con el sistema de creencias que incluye también a otros espacios naturales como cerros, la selva y cuevas.

Lo que sucede al final, es una falta al orden cosmogónico, porque el hecho de utilizar cohetes para pescar representa una irrupción violenta que provoca la aparición del jefe de los bobos. Es por esta razón, y también por su terquedad, que Lorenzo sufre una decaída que termina con su muerte. Por tanto, los motivos a considerar en este relato son: 1) transgresión del orden cosmogónico, 2) el agua y su relación con entidades sagradas o sobrenaturales, 3) el agua en forma de río, 4) la pesca como actividad económica y 5) el pez bobo como animal acuático.

El tercer ejemplo se titula Sobre el origen del maíz, del cual solo se informa que la versión es chinanteca:

Antiguamente la gente comía camote de plátanos en tortilla porque no encontraba otra cosa que comer.

- ¡Vamos a morir! — decía la gente, pero los ancianos decían:

— ¡Nosotros no vamos a morir! Vamos a ir al río, ahí, hay calabazas y sandías.

\footnotetext{
${ }^{4}$ Pez bobo: joturus pichardi (INAPESCA: 2014).

${ }^{5}$ Sobre la serpiente y su relación con el agua en otros pueblos mesoamericanos es interesante el trabajo de Héctor Medina (2018) y también el de Carlos Gerardo Hernández Paulino (2018).
} 
Se encontraron a un canoero y le dijeron:

— ¿A dónde vas tú?, nosotros no tenemos nada de comer.

El canoero dijo:

-Yo tengo todo en mi canoa.

Decía la gente:

-Déjanos las semillas del maíz.

Pero también decían que estaban sembrando tabaco.

—Entonces — dijo el canoero- eso sí lo voy a comprar.

Preguntaron al canoero:

— ¿De dónde viene el maíz? —Este dijo:

-El maíz viene de una tierra extraña.

— ¿Cuánto nos vas a vender?

- Tanto como tabaco tengan ustedes.

- Yo te voy a dar dos arrobas.

Los ancianos metieron el maíz en la boca diciendo que este maíz tenía muy buen aroma, le preguntaron:

— ¿Quién te ha mandado este maíz de tan buen aroma?

— ¿Un patrón!

Cada uno de ellos le dio un puro, y el canoero lo probó.

—PPor favor denme lumbre! —Y entonces el hombre a quien vendió el maíz tomó dos piedras y un trapo viejo e hizo lumbre.

-Ya ves, tenemos lumbre.

El canoero decía que él no sabía nada de cómo encender la lumbre. Él quería comprar todo el tabaco.

-Aquí vamos a hacer lumbre porque yo tengo mucha hambre. Ya hace dos días que estoy de camino.

- Aquí vamos a hacer comida - decía la gente.

-Aquí vamos a pescar.

- ¿Con qué vamos a coger a estos animales?

- Con una atarraya.

Y él pescó tres bobos grandes. El canoero no sabía lo que era un bobo.

- Yo voy a sembrar maíz y con este maíz voy a comer hasta que regreses otra vez.

El otro contestó:

-Es la única vez que yo vendré aquí.

-Pero entonces vamos a morir.

- ¿No puedes preguntar a Dios? - le dijeron al canoero.

- Si existe un Dios, ustedes van a ver cuándo viene la víspera.

Pero cuando vino la víspera llegó una tempestad y tronó mucho; toda la gente corrió lejos del canoero y decían que desde ahora tendrían mucho maíz.

Los ancianos que se habían quedado lejos del pueblo no creían que fuese cierto lo del maíz, y decían:

- Tal vez es un brujo, por eso tronó tanto.

El canoero solamente hablaba español y no sabía otro idioma. La gente estaba muy cansada y el hombre decía:

- ¡Déjalo!

Y entonces llegó a la media noche el canoero:

— ¿Cuánta gente son en total?

- Somos aproximadamente veinte.

-Está bueno, pero ustedes me van a dar el tabaco, estoy muy enojado por la tempestad, ¿no les había dicho que habrá una fiesta?

La gente preguntó:

— ¿Qué clase de fiesta de santo es ésta? Y el canoero contestó: 

sembrar.

- No les voy a decir a ustedes, pero van a comer la mitad del maíz y otra la van a

-Entonces - dijo el viejo- ¿qué tanto va a durar?

- Hasta que brote el maíz tres días va a durar y entonces habrá maíz.

Y el canoero dijo:

- La lluvia que mojó el maíz no es agua, sino que es la leche del maíz, es lo que toma el maíz.

—En tres días habrá maíz.

- Yo voy a esperar tres días.

Pero no fueron tres días, sino tres meses.

El canoero regresó otra vez para llevarse el tabaco, decía que vino desde muy lejos.

-Veinte días necesito yo y ¿qué cosas me van a regalar a mí?

Le preguntaron de dónde le habían traído el maíz.

— ¡Ah! — decía él— yo vengo de una tierra extraña, España, está muy lejos.

- ¿Qué cosa voy a comer en mi camino de regreso?

- Tú vas a llevar yuca, camote, calabaza, eso te vamos a dar.

— ¿Qué cosa es el camote? —el canoero preguntó:

-Es lo que has comido al medio día (le dieron todas esas cosas).

El canoero estaba muy contento.

-Estas cosas las vas a llevar para tu familia.

Él puso estas cosas en una olla con lumbre y en media hora todo estaba cocido, pero los camotes estaban demasiado calientes.

- ¿Por qué comes tú esto tan caliente?

- Yo tengo tanta hambre que ya me quemé toda la boca.

Le dieron agua fría para tomar y él escupió el agua y decía:

- iAhora va a llover leche de maíz!

La gente pensaba que él era un brujo, pero él decía:

-Yo no soy brujo.

Él era Cristo, porque trajo el maíz. Un viudo muy viejo le preguntó:

— ¿De dónde vienes tú?

-Él contestó.

- Vengo de la otra orilla del mar y de allá vino el maíz.

- Me vas a vender todavía un poco de maíz, porque si no, voy a morir.

El canoero le dijo:

-Tú no vas a morir.

El viejo le dio el dinero de su espalda y el canoero le dio un tenate de maíz diciendo:

— ¡Hasta que regrese yo con más maíz!

El viejo decía:

-iGloria a Dios!

$Y$ el canoero preguntó:

— ¿Qué cosa es esto de Dios?

— ¡Dios nos da fuerzas!

Contestó el viejo:

— ¿Cuántos dioses hay?

- Hay tres dioses.

— ¿A dónde está el primero?

—Está en la gloria, arriba está la gloria!

- ¿No conoces tú a Dios?

— ¿A dónde está ese Dios?

El canoero dijo:

-En el agua.

—Cómo se llama tu Dios?

-iSantiago! 
Dijo el canoero.

— ¿Quién es tu segundo Dios? — preguntó el canoero.

- Jesucristo

- ¿Y el tercero?

-Espíritu Santo.

—Estos tres están allá arriba y miran abajo de la tierra.

- Yo no sabía estas cosas porque todavía soy muy joven, fue Dios quien te ha mandado.

- Yo voy porque el agua está en mi Dios.

El canoero se fue y llevó todas estas plantas a su tierra adonde está el patrón del maíz.

_ ¿Cuándo vas a regresar otra vez?

- Cuando truene voy a regresar.

Entonces vino un viento muy fuerte y tronó el rayo y la gente decía:

—Es un brujo!

Pero el canoero no se fue, no se vio ninguna canoa, pero él había sembrado ya en la orilla camote, calabaza, etc. La gente esperaba hasta que este canoero regresara y la gente decía que viene de una tierra muy lejana.

Ahora todos tenemos maíz y toda la gente decía:

- Gracias porque este hombre ha venido, ahora sí tenemos picante, frijol, maíz, todo tenemos y ya no vamos a morir.

Algunas gentes creían que este canoero era un brujo, pero los ancianos decían que Dios le había mandado y que era Cristo, decía el viejo brujo que siempre anduvo con un garrote (Óp. cit.: 80-85).

Si bien este relato es extenso en comparación al resto, era relevante incluirlo por la mención de datos relacionados con el agua. En primera instancia aparece la figura del canoero, quizá el personaje más importante, debido a que es quien hace llegar el maíz a los chinantecos cuando sufrían una crisis. El canoero llegó porque navegó a bordo de una canoa, cuando esta forma de transporte era importante a mediados del siglo XX. Ahora ha caído en desuso en casi toda la región, aunque se mantienen las navegaciones en pequeñas chalupas o lanchas. Lo que sí se extinguió fue el transporte con fines comerciales, tal y como aun se aprecia en la narración, ya que el sistema de comunicación por carreteras o ferrocarriles son ahora los más importantes en cuanto a transporte de pasajeros y de mercancías.

Otro elemento importante es la pesca, una actividad que en el siglo pasado se realizaba con intensidad. En el texto se menciona la captura de peces bobos, una especie que durante mucho tiempo fue abundante en la región. Al día de hoy es raro escuchar a una persona decir que pescó un bobo, ya que por lo regular se habla de peces criados en las aguas retenidas de las presas o en establecimientos particulares. La mayoría consume pescado vendido en las pescaderías y es menor la cantidad de familias que consumen lo traído desde el río. Este fenómeno se ha observado especialmente en la ciudad de Tuxtepec y en las localidades de Chiltepec y Jacatepec.

Un tercer punto es la mención de que Dios está en el agua y que su nombre es Santiago. Este dato es interesante por sus sentidos cristianos, ya que el apóstol Santiago fue uno de los primeros en ser llamado por Jesús mientras pescaba con su hermano en el lago Genesaret (Mc 1: 19). Asimismo, es también testigo de una pesca milagrosa en el Lago de Tiberíades (Jn 21: 1-8), luego de que se habían hecho intentos infructuosos. En este sentido, la mención de este santo no es casual, tiene un sentido cercano con la actividad pesquera. Ahora bien, mi aproximación hermenéutica pudiera justificarse históricamente, debido a que desde los tiempos de la colonia española y en siglos 
recientes, elementos de la cosmovisión prehispánica se asociaron con la tradición judeocristiana, donde se agregaron para sitios con abundante agua, referencias a un santo simbólicamente relacionado ${ }^{6}$. Al respecto ya hicieron estudios José Velasco Toro y Gustavo Ramos Pérez (2011: 25-28). Si este ejemplo de mestizaje se dio para el caso de los nombres de las localidades, lo mismo sucedió en otros ámbitos de la cultura chinanteca, tal y como todavía se puede apreciar en la tradición oral.

Los motivos elegidos para la comparación son los siguientes: 1) el agua y su relación con entidades sagradas o sobrenaturales, 2) la pesca como actividad económica, 3) el pez bobo como animal acuático, 4) el agua en forma de río y 5) el agua como medio de transporte.

El último texto en este apartado es El armadillo y los bobos, que fue narrado por un interlocutor de nombre Sabino Contreras de San Lucas Ojitlán.

Una vez hubo una mancha de bobos, como seiscientos en el río Santa Rosa, y junto a ellos estaba un armadillo y la gente decía que por eso no se murieron los bobos cuando echaron cohetes al río. El armadillo estaba en el río.

- Vamos a usar dos cartuchos para una bomba - dijeron los hombres.

Y entonces hicieron cuatro bombas grandes y con estas murió el armadillo y hasta entonces pudieron pescar los bobos.

El armadillo era el jefe de los bobos (Ibíd.: 128)

Este relato, referido en el libro como mito, según mi opinión tiene más elementos para ser considerado una leyenda de acuerdo con los conceptos definidos anteriormente, ya que menciona aspectos históricos y geográficos que se han combinado con otros de carácter fantástico. No obstante, el texto es interesante porque dice que el «jefe»o «dueño» de los bobos es un armadillo, lo cual le hace coincidir con el relato La gente del río, que en su caso es una serpiente, en el sentido de que esta función también la pueden llevar a cabo animales que no son acuáticos. También coinciden en que ambos son de San Lucas Ojitlán, una localidad abajeña que en la década de 1970 sufrió por la construcción de la presa hidroeléctrica Cerro de Oro y que obligó a desplazar a poblaciones de dicho municipio. En este sentido, los relatos que se citan, de alguna manera son testimonios de un contexto previo a dicho evento, cuando los ríos y sus trayectos naturales aún permitían el arribo del popular pez bobo y que ya después de las construcciones decayó en abundancia, algo que así consideran los propios habitantes de las localidades.

Los motivos a considerar son los siguientes: 1) el agua en forma de río, 2) el pez bobo como animal acuático, 3) el agua y su relación con entidades sagradas o sobrenaturales, 4) la pesca como actividad económica y 5) transgresión del orden cosmogónico.

\section{RELATOS DE SANTA MARÍA JACATEPEC Y SAN JosÉ CHILTEPEC}

Para este apartado, el primer texto lo compilé en Jacatepec. La narradora fue la señora Hilda García León, quien relató lo siguiente sobre el culto a la Virgen de la Asunción, patrona de la localidad:

Nosotros honramos a la Virgen de la Asunción, 15 de agosto. Esa Virgen, pues desde que yo estoy chiquita sé que fue aparecida en una laguna. Según ha venido esa historia, llegó en una balsita. Por donde apareció allí pasaba el Camino Real, cruzando el terreno

${ }^{6}$ Están por ejemplo los casos de San Juan Bautista Tuxtepec, San Juan Bautista Valle Nacional o San Juan Bautista Tlacoatzintepec, localidades donde el santo en el toponímico tiene relación con el agua. 
de un señor que era el más rico del pueblo, por allí se iba uno siguiendo la orilla del río, pero antes de llegar a la parte baja había un recoveco así y ahí se formaba una laguna. Cuando crecía el río, el agua allí se acumulaba y así llegó esa imagen.

Dicen que una señora que fue al río a lavar su maíz, o a buscar agua, se la encontró en la balsa. Entonces corrió al pueblo a avisar lo que había encontrado. Y ya fueron los señores para rescatarla y uno de los señores más grandes se la llevó a su casa. Entonces hicieron una comisión para que fuera a ver al obispo a Oaxaca, porque entonces aquí no había ni sacerdote. Demoraron una semana en ir y venir. Vino el señor obispo y le hicieron una casita de palma a la Virgen, a un lado de donde está ahora la iglesia. Dicen que cuando el obispo la puso en esa capillita, la Virgen se volvió a regresar al río. Dicen, no me creas, porque quería que le hicieran su iglesia y tuvieron que hacérsela ${ }^{7}$.

Si bien la narración proviene de una localidad donde conviven familias de origen mestizo y chinanteco, sirve para mostrar cómo en la región el agua prosigue en la cosmovisión. La Virgen María de la Asunción llegó a Jacatepec a través del río, transportándose como cualquier persona lo hacía en la antigüedad, navegando en una balsa o en una chalupa. Si bien la Virgen es católica, no ha sido ajena al entorno cultural de la cuenca del Papaloapan, donde los ríos son ejes fundamentales de la cultura y la identidad regional. Sobre este relato los interlocutores subrayan cómo la Virgen fue la que eligió esta localidad para ser venerada, lo cual se aceptó con agrado. Sin embargo, los mismos informantes han dicho que con el tiempo San Jorge ha adquirido relevancia por diversas razones, entre las que destaca la fecha de su fiesta que se lleva a cabo el 23 de abril, la cual no se ubica en temporada de lluvias, como todavía sucede con la virgen de la Asunción, el 15 de agosto ${ }^{8}$.

Los motivos narrativos a considerar son los siguientes: 1) el agua en forma de río, 2) el agua en forma de laguna, 3) el agua como medio de transporte y 4) el agua y su relación con entidades sagradas o sobrenaturales.

El segundo relato fue entregado por los hermanos Ernesto y Marcelo Yescas Miguel. La grabación la hice en Santa Sofía, municipio de Jacatepec. El texto fue sobre la aparición de una sirena que encanta a los hombres que se acercan al río. Dice lo siguiente:

Mi tío cuenta que él vio en el río un pescado muy grande, y pues ese pescado él lo persiguió con tal de traérselo para comer, él lo siguió y lo siguió, verdad tú (le dice Ernesto a su hermano Marcelo, él dice «ajá» y Ernesto continúa su narración). Entonces a mi tío le gustaba mucho pescar allí, en ese tiempo que había mucho pescado. Y una de esas que perseguía al pescado grande, vio que ya no estaba y que de repente se salió del agua la sirena.

Dice mi tío que la sirena se le acercó y él estaba como tiesado, entonces la sirena lo quiso abrazar, pero mi tío se puso abusado y que le muerde la chiche a la sirena y le salió sangre, fue así que mi tío aprovechó para salirse del agua. Y ya fue como supuestamente ella lo soltó. No hombre, la sirena quería que se vivieran juntos, (que tuvieran relaciones como marido y mujer, interrumpe Marcelo), él se iba quedar muerto, pero su espíritu iba

${ }^{7}$ Entrevista formal realizada el 10 de marzo de 2015.

${ }^{8}$ Este fenómeno en la cuenca del Papaloapan ha sido observado por Guadalupe Vargas Montero (2011: 187-193), quien menciona que es común ver cómo a lo largo de la historia se han dado procesos de sustitución de una entidad católica por otra nueva. La situación no se ha dado plenamente en Jacatepec, porque el culto a la virgen María de la Asunción continúa; sin embargo los pobladores han demostrado que la celebración dedicada a San Jorge ha adquirido mayor relevancia en inversión económica y actividades festivas. 
a salir para irse con la sirena, pues, ¿sí me entiendes?, la sirena, cuenta el tío, era una mujer encuerada por arriba pero que tiene la cola del pescado ${ }^{9}$.

Este ejemplo, según la terminología citada, es una memorata porque narra la experiencia de una persona específica. Textos similares a este se han localizado en Vega del Sol y en el paraje San Martín, del mismo municipio, donde se cuenta cómo la sirena se ha aparecido en los balnearios turísticos. Este ser sobrenatural, según testimonios, vive en las partes más profundas de los ríos y sale por los orificios de donde nace el agua, al menos así lo refirieron en Santa Sofía, donde la sirena vive en el fondo del río, abajo, en un hueco pequeño que burbujea. Llama la atención que dicha creencia no es solo sobre este personaje, sino también sobre otros monstruos como el «pescado» gigante o la serpiente que cuida los «pescados». Ahora bien, los motivos a considerar son los siguientes: 1) el agua en forma de río, 2) la pesca como actividad económica, 3) el agua y su relación con entidades sagradas o sobrenaturales.

El tercer relato fue compartido por Rosa Dalia Martínez Manuel, de Vega del Sol, municipio de Jacatepec, lugar en donde hay un balneario llamado el Zuzul. El texto dice lo siguiente:

Antes el agua del Zuzul era chiquito. Era como un charco cuando llueve, ¿no? Era un lodazal porque criaban muchos marranos y ahí se iban a bañar. Así poco a poco los animales fueron escarbando y el brote de agua se fue haciendo más grande, pero alrededor estaban los árboles, estaba enmontado eso y se veía bonito. Y ya después vieron que sí brotaba agua limpia. Los marranos iban todavía, pero luego la gente los quitó porque vio que esa agua era limpia y la necesitaban. Ahora eso ya es balneario, pero antes era de agua que usaban para lavar, bañarse y también para tomar.

Una vez le pasó a mi papá una cosa rara allá en el Zuzul. Era temporada de secas y el agua se escaseó en la casa. Entonces él se levantó para acarrear un poco, igual como la gente lo hacía a las cinco de la mañana, creyó que era buena hora para ir; pero no, eran las cuatro de la madrugada. Pues se fue por sus dos galones ${ }^{10} \mathrm{y}$ le dio miedo porque todo estaba oscuro, más cuando el ojo de agua se encontraba rodeado de árboles. Cuando metió su galón para llenarlo, dijo que vio cómo algo se levantó, como una sirena, algo muy grande; esa cosa se brincó desde adentro y luego cayó salpicando mucha agua. Así lo hizo varias veces, se levantaba y luego se metía dentro del agua. Mi papá cuando vio eso se quedó tieso, un escalofrío pero fuerte le dio.

Cuando vino a la casa platicó todo, que había visto como una sirena y mi mamá le dijo que no debió irse tan temprano. No, pues sufrimos un poco, porque teníamos miedo de ir y cuando fuimos tratamos que fuera de día, aunque el agua estuviera más caliente ${ }^{11}$.

El Zuzul es un balneario que, especialmente en primavera, recibe centenares de visitantes provenientes de diferentes partes de la región y del país. Allí el turismo ha sido apoyado por autoridades locales, municipales, estatales e incluso federales a través de la Comisión Nacional para el Desarrollo de los Pueblos Indígenas (CDI) ${ }^{12}$. Según refieren los propios vecinos, esta actividad ha hecho que la localidad cambie sustancialmente a nivel de infraestructura y organizativo. No obstante, en la población se mantienen las narraciones tradicionales. Como se puede ver, la cita menciona que el balneario comenzó

\footnotetext{
${ }^{9}$ Entrevista realizada el 15 de mayo de 2015.

${ }^{10}$ Algunas personas les dicen galones a los recipientes o bidones que utilizan para llevar agua.

${ }^{11}$ Entrevista realizada el 6 de junio de 2016 en Vega del Sol.

${ }^{12}$ Que a partir de diciembre de 2018 cambió su nombre a Instituto Nacional de los Pueblos Indígenas (INPI).
} 
como un lodazal que utilizaban los animales de crianza. Con el tiempo se advirtió que el agua era limpia, útil y se destacó su singular belleza, después la narradora contó una memorata en la que su padre tuvo contacto con un ser extraño, al parecer una sirena. Algo similar sucede en el balneario San Martín, ubicado en el mismo municipio, donde los administradores mencionaron memoratas sobre personas que han encontrado peces gigantes, monstruos del agua e incluso sirenas. Los motivos narrativos para considerar aquí son: 1) el ojo de agua, 2) el agua y su relación con entidades sagradas o sobrenaturales y 3 ) el uso doméstico del agua.

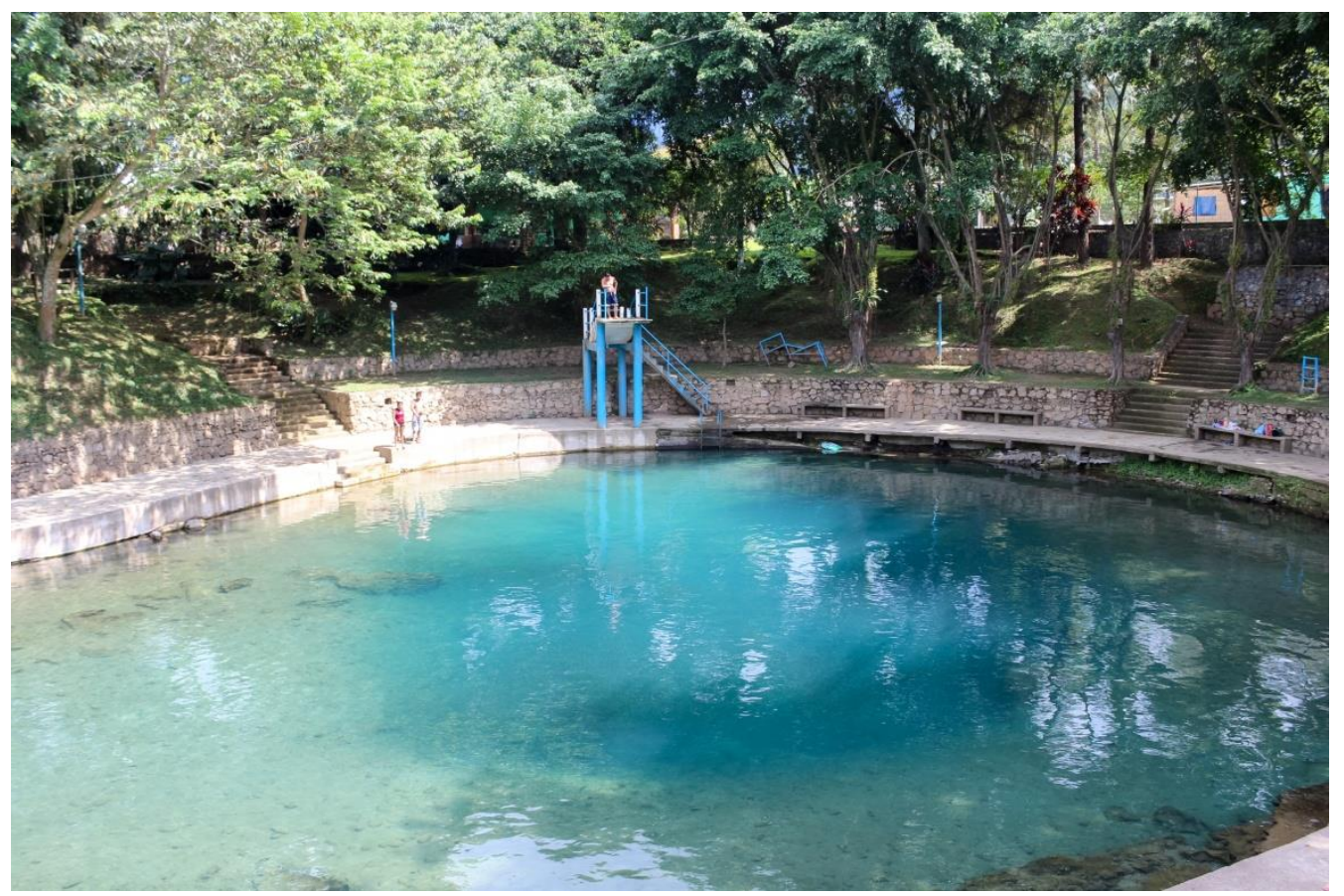

[Balneario El Zuzul de Vega del Sol, municipio de Jacatepec.] siguiente:

El cuarto relato es de Chiltepec, compartido por Ezequiel Juan Santiago. Dice lo

Fuimos con mi hermano a pescar al río, íbamos con otro muchacho, estaban chamacos, como de veinte y me llevaron a mí aunque tenía ocho años. Ellos estaban pescando y yo agarraba el bote de los pescados. Eran como las dos de la tarde, estábamos por donde está una peña, que era como un cerro mediano, que va desde allí hasta el puente donde pasan los carros. Estaba la hondura muy grande, ahora la gente ya no va, pero antes había mucho pescado y la gente iba a pescar. Yo ya sabía nadar, me dijeron «pásate de este lado, nosotros te vamos a llevar el pescado donde tú estás, en la orilla, nosotros vamos a la hondura», ahí estábamos, ya habíamos agarrado ocho pescados, cuando de repente sale uno de ellos. Dijo:

- Oye Melo - le dijo a mi hermano - si nos vamos por allá en medio hay un boquete con puerta donde sí cabemos, está muy estrecho, pero sí cabemos, aunque muy forzadito. Iba yo siguiendo un pescado chico, luego se me atravesó un robalo y me fui siguiendo ese robalo, el robalo se fue despacio y yo atrás; pero de pronto se me atravesó de frente un bobo, pues dejé atrás el robalo y me fui por el bobo porque es más fino. Entonces el bobo se metió por el boquete y yo ya no aguantaba la respiración, el bobo se salió y se volvió a meter, pero yo ya no aguantaba la respiración, solo me acerqué al hueco, alcance a meter la cara y vi que hay pescados como no te imaginas. Fue cuando me salí a agarrar aire, 
porque ya no aguantaba, salí quién sabe cómo. Y ahorita me asomé y vi que la puerta estaba cerrada.

En eso dijo mi hermano:

—Deja ir a ver —entonces se metió mi hermano y cuando volvió dijo-: es cierto, metí la cabeza y se ve como un horno grande, hay muchos pescados, como no te imaginas, unos muy grandes ¡Vamos a sacarlos!

— ¡No! — dijo el otro-, eso ha de ser cosa mala, ha de tener dueño, mejor no.

Ya después nos dijeron que ese lugar está encantado, porque año con año se oía música, como si hicieran fiesta y nadie veía nada. Con los años vimos que por allí se ahogaron varias personas. Por eso, qué bueno que ya no nos acercamos así como sea ${ }^{13}$.

Este ejemplo es interesante, porque la actividad pesquera en esta localidad, al igual que en gran parte de la Chinantla, tuvo un auge y vino a menos después de la construcción de la presa Cerro de Oro. Hasta entonces, aseguraron los informantes, la gente obtenía suficiente pescado incluyendo al pez bobo. El testimonio de Ezequiel Juan es parte de una memoria colectiva que refiere aquellos tiempos de bonanza. Ahora, según he observado, lo que le queda a la gente es el relato de las personas mayores. Aseguró que aún hay quienes salen a pescar, «pero lo que sacan no se compara con lo que se sacaba antes». De esta manera, en su testimonio puede considerarse que hay referencias a un "paraíso perdido», porque el río está cada vez más bajo, más «solitario» y solo se puede pescar en zonas específicas, aunque se mantiene la creencia de que en determinados lugares, poseedores de cierto encantamiento, hay abundantes peces de diferentes tamaños. Los motivos a considerar en esta ocasión son: 1) el agua en forma de río, 2) el agua y su relación con entidades sagradas o sobrenaturales, 3) la pesca como actividad económica y 4) el pez bobo y el robalo como animales acuáticos.

\section{SIMILITUDES Y DIFERENCIAS}

El agua como elemento presente en los relatos fue el punto de partida de esta investigación, sea a partir de ríos, ojos de agua o lagunas. En especial destaca la presencia del río, que es mencionado en la mayoría de los relatos. De los diecisiete compilados por mí, se menciona en catorce. Para el caso del libro de Weitlaner, las lagunas apenas son mencionadas en dos ocasiones. Al respecto, se presenta el siguiente cuadro sobre las formas que adquirió el agua.

\section{TABLA 1. MOTIVO: EL AGUA Y SUS FORMAS DE PRESENTACIÓN}

\begin{tabular}{|l|c|l|c|}
\hline \multicolumn{2}{|c|}{ Corpus de Robert J. Weitlaner } & \multicolumn{2}{c|}{ Corpus de 2015-2016 } \\
\hline \multicolumn{1}{|c|}{ Relato. } & Forma del agua & \multicolumn{1}{c|}{ Narradores } & Forma del agua \\
\hline $\begin{array}{l}\text { Sobre el padre y la } \\
\text { madre del maíz }\end{array}$ & Laguna & Hilda García León & Río y laguna \\
\hline La gente del río & Río & Hermanos Yescas & Río \\
\hline $\begin{array}{l}\text { Sobre el origen del } \\
\text { maíz }\end{array}$ & Río & $\begin{array}{l}\text { Rosa Dalia Martínez } \\
\text { Manuel }\end{array}$ & Ojo de agua \\
\hline $\begin{array}{l}\text { El armadillo y los } \\
\text { bobos }\end{array}$ & Río & Ezequiel Juan Santiago & Río \\
\hline
\end{tabular}

La tabla 1 demuestra que el río es importante en la narrativa chinanteca de ambos corpus, ya que se relaciona con actividades económicas, el consumo doméstico, el

\footnotetext{
${ }^{13}$ Entrevista con Ezequiel Juan Santiago (conocido como León Gallina), Chiltepec, 5 de mayo de 2016.
} 
transporte y es uno de los espacios donde las personas se vinculan con distintas entidades sagradas o sobrenaturales, sean santos católicos, dueños, sirenas u otras. En esto ambas compilaciones coinciden, a pesar de los cambios históricos. Aun así se mantiene la tradición oral sobre entidades sagradas o sobrenaturales, aunque los narradores contemporáneos por lo general fueron personas de la tercera edad, quienes matizaron que los hechos relatados sucedieron años atrás. En cambio, al referirse al tiempo presente, ellos subrayaron que la situación de los recursos hídricos ya no es la misma y eso en ocasiones lo evidenciaron en sus testimonios, tal y como sucedió en el último ejemplo. Otro asunto a distinguir es que en el corpus de Weitlaner hay mayor mención de los dueños, mientras que en el de Jacatepec y Chiltepec aparecen otros seres como la sirena, los chaneques, la Llorona o animales gigantes ${ }^{14}$. No obstante, ambos coinciden al referir entidades católicas. Para apoyar esta observación, véase la siguiente tabla sobre este motivo narrativo.

TABlA 2. MOTIVO: El AGUA Y SU RELACIÓN CON ENTIDADES SAGRADAS O SOBRENATURALES

\begin{tabular}{|c|c|c|c|}
\hline \multicolumn{2}{|c|}{ Corpus de Robert J. Weitlaner } & \multicolumn{2}{|c|}{ Corpus de 2015-2016 } \\
\hline Relato & Entidades & Narradores & Entidades \\
\hline $\begin{array}{l}\text { Sobre el padre y la } \\
\text { madre del maíz }\end{array}$ & $\begin{array}{l}\text { Padres o dioses del } \\
\text { maíz y del algodón. Se } \\
\text { muestran como aires o } \\
\text { rayos. }\end{array}$ & Hilda García León & $\begin{array}{l}\text { Virgen Santa María de } \\
\text { la Asunción. Se } \\
\text { manifiesta con su } \\
\text { aparición y movimiento. }\end{array}$ \\
\hline La gente del río & $\begin{array}{l}\text { La serpiente como } \\
\text { «jefe» o dueño de los } \\
\text { peces. Se manifiesta a } \\
\text { partir de su poder de } \\
\text { castigar a quien profana } \\
\text { sus dominios. }\end{array}$ & Hermanos Yescas & $\begin{array}{l}\text { La sirena como ser } \\
\text { sobrenatural se } \\
\text { manifiesta a partir de su } \\
\text { poder encantador. }\end{array}$ \\
\hline $\begin{array}{l}\text { Sobre el origen del } \\
\text { maíz }\end{array}$ & $\begin{array}{l}\text { Cristo, Santiago y el } \\
\text { espíritu santo } \\
\text { manifestados como } \\
\text { proveedores del maíz }\end{array}$ & $\begin{array}{l}\text { Rosa Dalia Martínez } \\
\text { Manuel }\end{array}$ & $\begin{array}{l}\text { La sirena como ser } \\
\text { sobrenatural. Se } \\
\text { manifiesta a partir de su } \\
\text { aparición. }\end{array}$ \\
\hline $\begin{array}{l}\text { El armadillo y los } \\
\text { bobos }\end{array}$ & $\begin{array}{l}\text { El armadillo como } \\
\text { dueño de los peces } \\
\text { bobos. Es un protector. }\end{array}$ & Ezequiel Juan Santiago & $\begin{array}{l}\text { No hay entidad sagrada } \\
\text { mencionada, pero se } \\
\text { cree la existencia de un } \\
\text { dueño de los peces. }\end{array}$ \\
\hline
\end{tabular}

Otra similitud importante es la presencia de animales acuáticos, en especial del pez bobo. Para el caso del corpus de Weitlaner, el pez bobo aparece como un recurso constante, actual y vigente en la actividad pesquera de los chinantecos de mediados del siglo XX. Mientras que para los relatos recientes, hay una gran diferencia: el pez bobo es una presa escasa para los pescadores. Esto lo he comprobado en distintas partes de la Chinantla baja, donde se me ha dicho que es un milagro encontrarlo y pescarlo, cuando en años pasados era abundante y una delicia que enriquecía la gastronomía tradicional. $\mathrm{Al}$ respecto, sirve retomar el relato de Ezequiel Juan Santiago, quien dijo que el pez bobo se podría encontrar en las honduras del río, por donde están las peñas o los sitios

\footnotetext{
${ }^{14}$ Los relatos sobre chaneques, la Llorona o animales gigantes serán estudiados en trabajos posteriores.
} 
encantados, tal y como lo sostiene en su relato de Chiltepec, empero, hoy día es difícil encontrarlo. Véase la tabla siguiente:

\section{TABLA 3. Motivo: ANIMALES ACUÁTICOS}

\begin{tabular}{|l|c|l|c|}
\hline \multicolumn{2}{|c|}{ Corpus de Roberto J. Weitlaner } & \multicolumn{1}{c|}{ Corpus de 2015-2016 } \\
\hline \multicolumn{1}{|c|}{ Relato } & Animal & Narradores & \multicolumn{1}{c|}{ Animal } \\
\hline $\begin{array}{l}\text { Sobre el padre y la } \\
\text { madre del maíz }\end{array}$ & Pez bobo & Hermanos Yescas & $\begin{array}{l}\text { Se habla de un pez } \\
\text { grande }\end{array}$ \\
\hline La gente del río & Pez bobo & $\begin{array}{l}\text { Rosa Dalia Martínez } \\
\text { Manuel }\end{array}$ & \\
\hline $\begin{array}{l}\text { Sobre el origen del } \\
\text { maíz }\end{array}$ & Pez bobo & Ezequiel Juan Santiago & Pez bobo y pez robalo \\
\hline $\begin{array}{l}\text { El armadillo y los } \\
\text { bobos }\end{array}$ & & & \\
\hline
\end{tabular}

En línea con la tabla anterior, se muestra el comportamiento del motivo sobre la pesca como actividad económica, la cual ha venido a menos, tal y como se mencionó anteriormente. La tabla quedaría de la siguiente manera:

\section{TABLA 4. MOTIVO: LA PESCA COMO ACTIVIDAD ECONÓMICA}

\begin{tabular}{|l|c|l|c|}
\hline \multicolumn{2}{|c|}{ Corpus de Roberto J. Weitlaner } & \multicolumn{1}{c|}{ Corpus de 2015-2016 } \\
\hline Relato & La pesca & Harradores & La pesca \\
\hline $\begin{array}{l}\text { Sobre el padre y la } \\
\text { madre del maíz }\end{array}$ & & Hermanos Yescas & $\mathrm{X}$ \\
\hline La gente del río & $\mathrm{X}$ & $\begin{array}{l}\text { Rosa Dalia Martínez } \\
\text { Manuel }\end{array}$ & \\
\hline $\begin{array}{l}\text { Sobre el origen del } \\
\text { maíz }\end{array}$ & $\mathrm{X}$ & Ezequiel Juan Santiago & $\mathrm{X}$ \\
\hline $\begin{array}{l}\text { El armadillo y los } \\
\text { bobos }\end{array}$ & $\mathrm{X}$ & & \\
\hline
\end{tabular}

Queda por mencionar otros motivos presentes, por ejemplo el uso doméstico del agua, la transgresión del orden cosmogónico y el agua como medio de transporte.

\section{TABLA 5. MOTIVOS DE MENOR APARICIÓN}

\begin{tabular}{|l|c|c|c|}
\hline \multirow{2}{*}{ Relatos } & \multicolumn{3}{c|}{ Motivos. } \\
\cline { 2 - 4 } & $\begin{array}{c}\text { Transgresión del orden } \\
\text { cosmogónico }\end{array}$ & $\begin{array}{c}\text { El agua como medio de } \\
\text { transporte }\end{array}$ & $\begin{array}{c}\text { El uso doméstico del } \\
\text { agua }\end{array}$ \\
\hline $\begin{array}{l}\text { Corpus de Roberto J. } \\
\text { Weitlaner }\end{array}$ & & & \\
\hline $\begin{array}{l}\text { Sobre el padre y la } \\
\text { madre del maíz }\end{array}$ & $\mathrm{X}$ & & $\mathrm{X}$ \\
\hline La gente del río & $\mathrm{X}$ & $\mathrm{X}$ & \\
\hline $\begin{array}{l}\text { Sobre el origen del } \\
\text { maíz }\end{array}$ & & & \\
\hline $\begin{array}{l}\text { El armadillo y los } \\
\text { bobos }\end{array}$ & $\mathrm{X}$ & $\mathrm{X}$ & \\
\hline Corpus de 2015-2016 & & & \\
\hline Hilda García León. & & & \\
\hline Hermanos Yescas. & & & \\
\hline
\end{tabular}




\begin{tabular}{|l|l|l|c|}
\hline Rosa Dalia Martínez & & & $\mathrm{X}$ \\
Manuel & & & \\
\hline $\begin{array}{l}\text { Ezequiel Juan } \\
\text { Santiago }\end{array}$ & & \\
\hline
\end{tabular}

Respecto a la transgresión del orden cosmogónico, en dos casos se menciona el uso de explosivos para obtener, en la pesca, mejores resultados. En una de esas ocasiones, en La gente del río, un personaje muere. En la otra, El armadillo y los bobos, la transgresión posibilita la pesca, no dice si hubo consecuencias, aunque en casi todos los textos que tienen este motivo, sea en las actividades pesqueras o en la cacería, se exponen los resultados, que por lo general son negativos para los transgresores. La presencia de este motivo no ha sido recurrente en la narrativa compilada por mí, empero, resulta curioso que en numerosos testimonios de informantes, que no son estrictamente narraciones, se haga mención de que los problemas actuales para obtener pescado se deban precisamente a la constante alteración que se ha hecho sobre el medio ambiente. En los municipios de la zona baja, Chiltepec, Jacatepec, Ojitlán o Valle Nacional se me ha dicho que hoy día son contadas las personas que muestran respeto a los dueños de los peces, de las cuevas, de los animales y si los problemas se han agravado se debe a los cambios sociales que han alterado el orden natural tal y como lo menciona Joel Avendaño, citado páginas arriba. Algo similar sucede con el uso del agua como medio de transporte, una actividad que se dejó precisamente por las mismas causas. Por último, en el uso doméstico del agua, hay coincidencia entre los dos corpus, aunque su mención como motivo narrativo ha sido menos recurrente. No obstante, las observaciones etnográficas demuestran que los ríos, las lagunas y los arroyos se utilizan con frecuencia para el consumo doméstico, el lavado de ropa, el aseo personal, el esparcimiento, el mantenimiento del ganado y el apoyo en los sistemas de riego.

\section{CONCLUSIONES}

En la Chinantla el agua es más que un recurso económico, es un elemento fundamental para comprender cómo la población chinanteca y mestiza se percibe a sí misma en el mundo y en su historia. Es decir, los ríos, los nacimientos y las lagunas son parte de la cosmovisión, la cual, desde el punto de vista de los pobladores, concibe a la naturaleza como algo poblado de entidades sagradas, sobrenaturales y que resultan de procesos culturales de encuentro entre el sistema de creencias prehispánico y el judeocristiano, conformando así un entramado mestizo y cambiante. En especial, son dignas de observación las entidades conocidas como dueños, padres, madres o jefes que ayudaban a mantener el orden y el equilibrio ecológico, tal y como se mencionan en el corpus de Roberto J. Weitlaner ${ }^{15}$. Al parecer su sistema de creencias tenía en el fondo un fin discursivo de preservación de los recursos, algo que, según se observa en la narrativa contemporánea y en las declaraciones de los informantes, ha reducido su presencia a causa de los cambios acelerados y dirigidos por los gobiernos de México desde la mitad del siglo XX. No obstante, permanecen en la producción narrativa otros seres sobrenaturales importantes que podrían haber tenido la función de dueños en el pasado, me refiero a los peces gigantes, las sirenas y otros que no se pudieron exponer en este trabajo por su extensión o por la necesidad de estudiarlos en futuros trabajos, me refiero a la Llorona, la Matlacihua, los chaneques y los nahuales.

${ }^{15}$ Respecto a esta preocupación por mantener el equilibrio con el mundo circundante, en el cual es prioritario el tema del agua, ha sido interesante consultar el trabajo de Anuschka van't Hooft (2006) donde hace también un análisis de relatos tradicionales y de personajes sobrenaturales. 
Lo que me he propuesto demostrar hasta aquí es que desde mediados del siglo XX a la fecha, el agua se ha mantenido como un tópico recurrente en la tradición oral de los chinantecos, especialmente en la subregión baja, y más en concreto en los municipios de Jacatepec y Chiltepec. Por medio de la comparación con el corpus que dejó Robert. J. Weitlaner, he podido observar no solo la constancia de entidades sagradas $o$ sobrenaturales, también he visto otros motivos recurrentes, como son la actividad pesquera, la mención de animales acuáticos y el uso doméstico del agua, todos estos demostrando la trascendencia sistémica que tienen los recursos hídricos en la cultura chinanteca. Al respecto, es evidente que faltan más estudios, ya sea en las zonas medias y altas de la Chinantla, asimismo, se requiere de un proceso de investigación más profundo que vaya más allá de la tradición oral, para tener en cuenta otros procesos culturales, como la gastronomía, tal y como sucede en San Felipe Usila y San Juan Bautista Tlacoatzintepec. Por el momento, sirva este trabajo como un comienzo para el estudio de una relación íntima entre sociedad chinanteca, los recursos naturales como el agua, la cosmovisión y los procesos sociales que han sucedido y suceden en su historia.

\section{BIBLIOGRAFÍA}

Bartolomé, Miguel Alberto y Barabas, Alicia (1990): La presa Cerro de Oro y El Ingeniero El Gran Dios, Tomo II, Colección Presencias, México, INI y CONACULTA.

BEVAN, Bernard (1987): Los chinantecos y su hábitat (Primera edición), Colección INI, número 75, México, INI.

CuÉllar, E., D. (2013): «Variantes regionales en textos narrativos sobre la Xtabay: Chiapas, Yucatán y Quintana Roo», en Variación regional en la narrativa tradicional de México, Aurelio González, Nieves Rodríguez Valle y Mercedes Zavala Gómez del Campo (Eds.), México, El Colegio de México y El Colegio de San Luis, pp. 123-131.

De TeresA, Ana Paula (2011): Quia-Na. La selva chinanteca y sus pobladores (Primera edición), México, UAM-I y Juan Pablos Editor.

GARCÍA HernándeZ, Tomás (1997): Tuxtepec ante la historia, Tuxtepec, México, Culturas Populares-CONACULTA.

GoNZÁLEZ, Raúl Eduardo (2014): «Motivos y fórmulas en los corridos terracaleños de valientes», en Temas y motivos en formas narrativas de la literatura tradicional de México, Claudia Carranza y Mercedes Zavala Gómez del Campo (Eds.), San Luis Potosí, México, El Colegio de San Luis, pp. 61-76.

Good Eshelman, Catharine (2001): «El ritual y la reproducción de la cultura: ceremonias agrícolas, los muertos y la expresión artística entre los nahuas de Guerrero», en Cosmovisión, ritual e identidad de los pueblos indígenas de México, Johana Broda y Félix Báez-Jorge. (Coords.), México, CONACULTA y FCE, pp. 239-297.

HeRnÁndeZ PAulino, Carlos Gerardo (2018): «La leyenda de la culebra de agua protectora del pueblo de San Bernardo (Oaxaca, México): sustrato mítico zapoteco y dispersión pluricultural», Boletín de Literatura Oral, Vol. 8, pp. 165176. DOI: https://doi.org/10.17561/blo.v8.9

MEDinA MiRANDA, Héctor M. (2018): «Recursos hídricos y cosmografía wixarika», Relaciones. Estudios de historia y sociedad, 39 (156), pp. 195-223. 
DOI: https://doi.org/10.24901/rehs.v39i156.319

Medrano de LunA, Gabriel y PedrosA, José Manuel (2018): «El Mágico que hizo pacto con el diablo, relato oral de Sshinda, narrador y juguetero otomí», Revista de Literaturas Populares, XVIII (1), 73-114.

MolinARI, María Sara y Aguilar MedinA, José Íñigo (2013): «Cosmovisión de la vida cotidiana en Chiltepec, Oaxaca», Diario de campo, 12, pp. 19-56.

RAMíREZ GONZÁLEZ, Martha Isabel (2012): Temas, motivos y tópicos en la narrativa tradicional de la región de los Altos de Guanajuato (Tesis de maestría), San Luis Potosí, México, El Colegio de San Luis.

TAGgART, James M. (1983): Nahuat myth and social structure, Estados Unidos, University of Texas Press.

ThiÉBAUT, Virginie (2013): «Paisaje e identidad. El río Papaloapan, elementos funcional y simbólico de los paisajes del Sotavento», Liminar. Estudios sociales y humanísticos, XI (2), pp. 82-99. DOI: https://doi.org/10.29043/liminar.v11i2.224

VAN'T HOOFT, Anuschka (2006): «La sirena que inunda: una reconstrucción de la comunidad nahua de la Huasteca a través de su tradición oral», en Comunicación desde la periferia: tradiciones orales frente a la globalización, Luz María Lepe y Osvaldo Granda (Eds.), México, Anthropos y Tecnológico de Monterrey (campus Toluca), pp. 19-30.

VELASCO TORO, José y RAMOs PÉREZ, Gustavo (2011): «Agua: símbolo de vida y muerte en el Bajo Papaloapan», en Mariposas en el agua. Historia y simbolismo en el Papaloapan, Luis A. Montero, Israel Sandré, Osorio y José Velasco Toro (Coords.), México, Universidad Veracruzana, pp. 21-46.

WeITlANER, Robert J. (1977): Relatos, mitos y leyendas de la Chinantla (Selección, Introducción y Notas de María Sara Molinari, María Luisa Acevedo y Marlene Aguayo Alfaro). México, INI.

Weitlaner, Robert J. y CAStro, Carlo Antonio (1973): Papeles de la Chinantla VII. Usila (Morada de colibríes), México, Museo Nacional de Antropología.

ZAMORANO CASAL, Francisco Manuel (2007): Turismo alternativo. Servicios turísticos diferenciados. Animación, turismo de aventura, turismo cultural, ecoturismo, turismo recreativo, México, Trillas. 